\title{
Short Trends and Associated Factors of Cognitive Impairment in a Population at High Cardiovascular Risk
}

li yang

Zhejiang Hospital https://orcid.org/0000-0003-4265-454X

shiyun hu

zhe jiang hospital

xiaoling xu

zhejiang hospital

yanying huang

zhejiang hospital

cheng xuan

zhejiang hospital

caiyan yu

zhejiang hospital

pinpin zheng

fudan university

jing yan ( $\sigma$ phoebe84331@163.com)

Zhejiang Hospital

Research article

Keywords: dementia, short trends, associated factors, cardiovascular disease, older people

Posted Date: January 15th, 2021

DOI: https://doi.org/10.21203/rs.3.rs-144628/v1

License: (9) (1) This work is licensed under a Creative Commons Attribution 4.0 International License. Read Full License 


\section{Abstract}

Background: It has been proposed that some risk factors of cardiovascular disease

(CVD) are associated with and contribute to the development of all cause of dementia. Our aim was to examine the short trends and associated factors of cognitive impairment among a eastern Chinese population at high risk of CVD.

Methods: We used a convenience sampling strategy to select 7 subdistricts in Zhejiang province, which was a part of China Patient-Centered Evaluative Assessment of Cardiac Events (PEACE) project. Participants in 2018 (n=3089) and in 2020 ( $n=3082)$ at high risk of CVD in Zhejiang province with registry for the PEACE Project. Participants completed $3+$ neuropsychological evaluations including of Mini-Mental State Examination (MMSE), Montreal Cognitive Assessment (MoCA) and Hospital Anxiety and Depression Scale (HAD) tests. Age-, gender- standardized prevalence rates were calculated based on the sixth population census for population of China. Cox proportional hazards regression models to estimate hazard ratios (HR) for the associations between the risk for all-cause dementia. Trial registration number was NCT02536456.

Results: There was an increase prevalence of dementia and $\mathrm{MCl}$ among the individuals at high risk of CVD between 2018 and 2020. It showed that older age, lower education levels, having a medical history of hypertension, stroke and diabetes, having the family history of hypertension, heavy drinking, depression, and obesity were associated with dementia, while female might be a protective factor for dementia.

Conclusion: More population-based strategies should be focusing on modifiable risk factors of dementia, such as CVD risk factors.

\section{Background}

Dementia has been considered as a public health priority as it commonly leads to increase in terms of disability, mortality, and cost [1,2]. The number is expected to reach 152 million by 2050, with about 60 to $70 \%$ of them suffering from Alzheimer's disease (AD). Mild cognitive impairment (MCl) is identified as an intermediate state that cognitive impairment does not reach the threshold for dementia diagnosis, which is associated with increased risk of dementia $[3,4]$. Some studies suggest that key cardiovascular risk factors, such as hypertension, diabetes, and hypercholesterolemia influence the incidence of dementia [5-7].

As the country with the world's largest population, China is facing substantial challenges in ageing population, of which increasing numbers will have some degree of dementia and cardiovascular disease (CVD). At present, there are about 10 million AD patients in China, and it is estimated that by 2050, the number of patients will exceed 40 million. Zhejiang province is located in eastern China, people that aged 60 or above accounted for $21.77 \%$ of the total population by the end of 2017 [4, 8]. And the incidence of CVD among the participants with high risk of CVD is about $3.9 \%$ in 2014 to 2016, and is expected to increase to $5 \%$ by 2021 [9]. But there are few epidemiological data available on dementia in eastern China, which taking into account of CVD risk factors.

Our study explores the short trends and associated factors of dementia prevalence among population at high CVD risk in eastern China for the years 2018 and 2020.

\section{Methods}


It is a population-based closed cohort assembled in April 2018 and June 2020 in Zhejiang province, representative of dwellers 55 years or more at high risk of CVD. This project is part of the China Patient-Centered Evaluative Assessment of Cardiac Events (PEACE) Million Persons Project, which has been described previously [10].

Then participants were given cognitive function evaluation and diagnosis. The criteria of high risk of CVD had been described previously $[10,11]$. The baseline sample was initially interviewed in $2018(N=3500)$, and the replenishment sample was interviewed in 2020, with 1724 of whom were continuing and the others interviewed for the first time. The central ethics committee at the China National Center for Cardiovascular Disease (NCCD) and Zhejiang hospital approved this project. Written informed consent is obtained from all literate participants without cognitive decline on entry into the project. And for illiterate participants or ones with cognitive decline, their informed consent is obtained from their literate legally authorized representatives. Trial registration number: NCT02536456.

\section{Assessments}

The cognitive function evaluation was carried out by a multidisciplinary team comprised of a nurse and a neurologist. Participants were classified into three categories: normal cognitive function, $\mathrm{MCl}$ and dementia. Screening was performed using the Mini-Mental State Examination (MMSE), the Montreal Cognitive Assessment (MoCA), the Hospital Anxiety and Depression Scale (HAD) tests [12]. Participants who scored below the MMSE cutoff points of 20 for 0-2 years, 23 for 3-6 years and 27 for 7 years or more of schooling were considered as positive results, which had the tendency of dementia [13]. Participants who scored less than the MoCA cutoff points of 1.5 standard deviations (SD) or more below age- and education-adjusted norms were considered as $\mathrm{MCl}$ [14]. HAD tests included two sub-scales of anxiety $(A)$ and depression (D), the sub-scale of anxiety and depression was abnormal with a score below 8 [15].

The confirmed diagnosis of dementia was conducted among the subjects with positive results of MMSE test. The diagnostic criteria of dementia used the Chinese guidelines for the diagnosis and treatment of dementia and cognitive impairment [16]. There were no questionnaires or measures used in our study require a license in order to administer them.

\section{Statistical analysis}

Characteristics, cognitive function status of participants were summarized using percentages or means and SD, and they were compared by Student's $t$ tests and $X^{2}$ tests, respectively. Age-, gender- standardized prevalence rates were calculated based on the population distribution of China in 2010 (the sixth population census for population of China) [17].

We used Cox proportional hazards regression models to estimate hazard ratios (HR) and 95\% Cls for the associations between the risk for all-cause dementia. Crude regression models were first used to assess the risk factors associated with dementia among population at high risk of CVD, then adjusted regression models were used to ascertain the risk factors considering the main effects of sociodemographic characteristics. 2-sided significance tests were used for all analyses, with statistical significance set at P<0.05. SAS 9.2 (SAS Institute Inc., Cary, NC, USA) for data management and analysis.

\section{Result}

\section{Characteristics of the population}

The characteristics of the population matched cohort were displayed in Table 1. A total of 3500 residents were enrolled in this project in 2018, and 3089 ones completed the survey. The replenishment sample was interviewed in 
2020, with 1724 ones were continuing and 1358 interviewed for the first time in 2020. 
Table 1

Characteristics of the 2018 and 2020 Cohorts

\begin{tabular}{|c|c|c|c|c|}
\hline Characteristic & $2018(n=3089)$ & $2020(n=3082)$ & $\mathrm{X} 2 / \mathrm{t}$ & $\mathbf{P}$ \\
\hline Age, y & & & 269.13 & $<0.0001$ \\
\hline $55-64$ & $986(31.94)$ & $622(20.24)$ & & \\
\hline $65-74$ & 1759 (56.98) & 1920 (82.48) & & \\
\hline$\geq 75$ & $342(11.08)$ & $540(17.52)$ & & \\
\hline Mean (SD) & $67.07(12.45)$ & $69.30(5.03)$ & -40.27 & $<0.0001$ \\
\hline Gender & & & 1.03 & 0.3112 \\
\hline Male & $1472(47.65)$ & $1429(46.37)$ & & \\
\hline Female & $1617(52.35)$ & $1653(53.63)$ & & \\
\hline Education & & & 32.36 & $<0.0001$ \\
\hline Illiterate (< 1 year) & $584(18.91)$ & $486(15.77)$ & & \\
\hline Primary ( $1-6$ years) & 1569 (50.79) & $1715(55.65)$ & & \\
\hline Middle (7-12 years) & $901(29.17)$ & $872(28.29)$ & & \\
\hline High (> 13 years) & $35(1.13)$ & $9(0.29)$ & & \\
\hline \multicolumn{5}{|l|}{ Cardiovascular risk factors } \\
\hline Stroke & $145(4.69)$ & $123(3.99)$ & 1.8382 & 0.1752 \\
\hline Diabetes & $228(7.38)$ & $202(6.55)$ & 1.628 & 0.202 \\
\hline $\mathrm{CHD}$ & $50(1.62)$ & $37(1.20)$ & 1.9478 & 0.1628 \\
\hline Hypertension & $1411(45.68)$ & $1437(46.63)$ & 0.5571 & 0.4554 \\
\hline \multicolumn{5}{|l|}{ Lifestyle habits } \\
\hline Cigarette smoking & $422(16.99)$ & $424(13.76)$ & 1619.32 & $<0.0001$ \\
\hline Heavy alcohol drinking & $724(29.15)$ & $1116(36.21)$ & 639.06 & $<0.0001$ \\
\hline Regular exercise & $281(11.29)$ & $423(13.72)$ & 3110.85 & $<0.0001$ \\
\hline Anxiety & $89(2.88)$ & $32(1.04)$ & 5696.49 & $<0.0001$ \\
\hline Depression & $468(15.15)$ & $477(15.48)$ & 2969.85 & $<0.0001$ \\
\hline BMI, Mean (SD) & $25.22(3.11)$ & $25.17(3.07)$ & 0.54 & 0.5862 \\
\hline SBP, mm Hg, Mean (SD) & 160.95 (20.09) & 162.18 (19.97) & -2.16 & 0.0309 \\
\hline DBP, mm Hg, Mean (SD) & $86.56(11.32)$ & $86.83(11.30)$ & -0.83 & 0.408 \\
\hline TC, mmol/L, Mean (SD) & $5.28(1.31)$ & $5.33(1.28)$ & -1.42 & 0.1552 \\
\hline TG, mmol/L, Mean (SD) & $2.04(1.16)$ & $1.97(1.11)$ & 1.92 & 0.0549 \\
\hline LDL-C, mmol/L, Mean (SD) & $2.95(1.15)$ & $2.96(1.13)$ & -0.28 & 0.7828 \\
\hline
\end{tabular}




\begin{tabular}{|lllll|}
\hline Characteristic & $\mathbf{2 0 1 8}(\mathbf{n = 3 0 8 9})$ & $\mathbf{2 0 2 0}(\mathbf{n = 3 0 8 2})$ & $\mathbf{X 2} / \mathbf{t}$ & $\mathbf{P}$ \\
\hline HDL-C, mmol/L, Mean (SD) & $1.48(0.45)$ & $1.52(0.45)$ & -3.57 & 0.0004 \\
\hline MMSE scores, Mean (SD) & $23.33(7.13)$ & $22.23(3.18)$ & 7.87 & $<0.0001$ \\
\hline MoCA scores, Mean (SD) & $18.17(5.60)$ & $18.10(4.36)$ & 0.5 & 0.6146 \\
\hline Had scores, Mean (SD) & $7.56(5.22)$ & $9.59(3.52)$ & -17.87 & $<0.0001$ \\
\hline
\end{tabular}

\section{Prevalence trend of dementia and $\mathrm{MCl}$}

Table 2 displayed the prevalence and adjusted prevalence of individuals in each cognitive function category stratified by age groups (55-64 years, 65-74 years, and $\geq 75$ years) in 2018 and 2020 . The data showed an increase prevalence of dementia among the individuals aged 55 years or older at high risk of CVD between 2018 and 2020 ( $8.68 \%$ in 2018 compared with $10.15 \%$ in $2020, \mathrm{P}<0.05$ ). The prevalence of $\mathrm{MCl}$ also increased significantly across the 2 cohorts from $22.04-25.46 \%(P<0$.05). And the data showed an increase trend of dementia and $\mathrm{MCl}$ prevalence with the increase of age $(P<0.05)$.

Table 2

Cognitive Function, by Age Range, 2018 and 2020 Cohorts

\begin{tabular}{|c|c|c|c|c|c|c|c|c|c|c|}
\hline \multirow[b]{2}{*}{$\begin{array}{l}\text { Cognitive } \\
\text { Function }\end{array}$} & \multicolumn{2}{|c|}{$55-64$ y } & \multicolumn{2}{|l|}{$65-74$ y } & \multicolumn{2}{|l|}{$75-y$} & \multicolumn{2}{|c|}{$\begin{array}{l}\text { Total (Age } \geq 35 \\
\text { y) }\end{array}$} & \multicolumn{2}{|c|}{$\begin{array}{l}\text { Adjusted } \\
\text { prevalence }\end{array}$} \\
\hline & $\begin{array}{l}2019 \\
(n= \\
988)\end{array}$ & $\begin{array}{l}2020 \\
(n= \\
622)\end{array}$ & $\begin{array}{l}2019 \\
(n= \\
1759)\end{array}$ & $\begin{array}{l}2020 \\
(\mathrm{n}= \\
1920)\end{array}$ & $\begin{array}{l}2019 \\
(n= \\
342)\end{array}$ & $\begin{array}{l}2020 \\
(n= \\
540)\end{array}$ & $\begin{array}{l}2019 \\
(n= \\
3089)\end{array}$ & $\begin{array}{l}2020 \\
(n= \\
3082)\end{array}$ & $\begin{array}{l}2019 \\
(n= \\
3089)\end{array}$ & $\begin{array}{l}2020 \\
(\mathrm{n}= \\
3082)\end{array}$ \\
\hline $\begin{array}{l}\text { Normal } \\
\text { cognitive } \\
\text { function }\end{array}$ & $\begin{array}{l}836 \\
(84.6) \\
{[82.0-} \\
90.2]\end{array}$ & $\begin{array}{l}475 \\
(76.4) \\
{[68.7-} \\
81.2]\end{array}$ & $\begin{array}{l}1082 \\
(61.5) \\
{[56.2-} \\
71.3]\end{array}$ & $\begin{array}{l}1172 \\
(61.0) \\
{[56.5-} \\
78.1]\end{array}$ & $\begin{array}{l}191 \\
(55.9) \\
{[77.5-} \\
81.2]\end{array}$ & $\begin{array}{l}294 \\
(54.4) \\
{[41.6-} \\
65.1]\end{array}$ & $\begin{array}{l}2109 \\
(68.3) \\
{[56.9-} \\
73.5]\end{array}$ & $\begin{array}{l}1941 \\
(63.0) \\
{[55.5-} \\
70.1]\end{array}$ & $\begin{array}{l}2109 \\
(69.3) \\
{[58.9-} \\
78.5]\end{array}$ & $\begin{array}{l}64.39 \\
{[60.4-} \\
71.2]\end{array}$ \\
\hline $\begin{array}{l}\text { Mild } \\
\text { cognitive } \\
\text { impairment }\end{array}$ & $\begin{array}{l}90 \\
(9.1) \\
{[7.8-} \\
12.0]\end{array}$ & $\begin{array}{l}86 \\
(13.8) \\
{[11.2-} \\
15.7]\end{array}$ & $\begin{array}{l}462 \\
(26.26) \\
{[24.7-} \\
28.9]\end{array}$ & $\begin{array}{l}507 \\
(26.41) \\
{[24.5-} \\
28.2]\end{array}$ & $\begin{array}{l}98 \\
(28.60) \\
{[37.7-} \\
41.3]\end{array}$ & $\begin{array}{l}157 \\
(29.07) \\
27.4- \\
31.1]\end{array}$ & $\begin{array}{l}650 \\
(21.0) \\
{[18.8-} \\
23.7]\end{array}$ & $\begin{array}{l}750 \\
(24.33) \\
22.8- \\
25.8]\end{array}$ & $\begin{array}{l}650 \\
(22.04) \\
{[18.8-} \\
23.7]\end{array}$ & $\begin{array}{l}25.46 \\
{[24.1-} \\
27.8]\end{array}$ \\
\hline Dementia & $\begin{array}{l}62 \\
(6.3) \\
{[4.8-} \\
7.9]\end{array}$ & $\begin{array}{l}61 \\
(9.8) \\
{[7.6-} \\
12.3]\end{array}$ & $\begin{array}{l}215 \\
(12.22) \\
{[10.7-} \\
13.7]\end{array}$ & $\begin{array}{l}241 \\
(12.55) \\
{[10.9-} \\
14.1]\end{array}$ & $\begin{array}{l}53 \\
(15.47) \\
{[18.8-} \\
21.7]\end{array}$ & $\begin{array}{l}89 \\
(16.48) \\
{[14.1-} \\
18.7]\end{array}$ & $\begin{array}{l}330 \\
(10.7) \\
{[8.1-} \\
12.4]\end{array}$ & $\begin{array}{l}391 \\
(12.69) \\
{[11.5-} \\
13.9]\end{array}$ & $\begin{array}{l}330 \\
(8.68) \\
{[7.1-} \\
12.4]\end{array}$ & $\begin{array}{l}10.15 \\
{[7.4-} \\
12.3]\end{array}$ \\
\hline
\end{tabular}

\section{Associated risk factors}

Table 3 reported the results of 2 Cox proportional hazards regression models with the presence of dementia as the outcome variable, using pooled 2018 and 2020 data. Model 1 showed the unadjusted univariate models, and Model 2 showed the multivariate models adjusted by age, gender and education levels. It showed that older age including the age range of $65-75$ (adjusted hazard ratio $[\mathrm{AHR}]=1.77,95 \% \mathrm{Cl}: 1.24-2.52)$ and 75 or more $(\mathrm{AHR}=3.19,95 \% \mathrm{Cl}: 2.00-$ $5.05)$ compared with the age range of $55-64$, lower education levels including primary $(\mathrm{AHR}=1.44,95 \% \mathrm{Cl}$ : $1.05-$ 1.97) and middle or more (AHR $=1.43,95 \% \mathrm{Cl}$ : 1.00-2.14) compared with illiterate, having a medical history of hypertension $(A H R=1.37,95 \% \mathrm{Cl}: 1.03-1.83)$, stroke $(A H R=2.31,95 \% \mathrm{Cl}: 1.47-3.63)$ and diabetes $(A H R=1.76,95 \%$ $\mathrm{Cl}$ : 1.42-2.37), having the family history of hypertension ( $\mathrm{AHR}=1.61,95 \% \mathrm{Cl}: 1.14-2.28)$, heavy drinking $(\mathrm{AHR}=1.56$, $95 \% \mathrm{Cl}: 1.00-2.17)$, depression $(\mathrm{AHR}=1.59,95 \% \mathrm{Cl}: 1.04-3.00)$, and obesity $\left(\mathrm{BMI} \geq 30.0 \mathrm{~kg} / \mathrm{m}^{2}\right)$ compared with normal 
$\left(\mathrm{BMI}=18.5-24.9 \mathrm{~kg} / \mathrm{m}^{2}\right)$ were associated with dementia, while female (AHR $\left.=0.57,95 \% \mathrm{Cl}: 0.41-0.78\right)$ might be a protective factor for dementia. 
Table 3

Relative Risks for Presence of Dementia

\begin{tabular}{|c|c|c|}
\hline & Models, RR (95\% & \\
\hline Variable (ref. 55-64) & Model $1^{a}$ & Model $2^{b}$ \\
\hline Age, y & & \\
\hline $65-74$ & $0.79(0.63-1.00)$ & $1.77(1.24-2.52)$ \\
\hline$\geq 75$ & $2.34(1.76-3.12)$ & $3.19(2.00-5.05)$ \\
\hline Gender (ref. Male) & & \\
\hline Female & $0.58(0.46-0.74)$ & $0.57(0.41-0.78)$ \\
\hline Education (ref. Illiterate) & & \\
\hline Primary (1-6 years) & $1.19(0.95-1.49)$ & $1.44(1.05-1.97)$ \\
\hline Middle or more ( $\geq 7$ years) & $1.48(1.13-1.93)$ & $1.43(1.00-2.14)$ \\
\hline State of marriage (ref. Marri & & \\
\hline living alone & $1.10(0.75-1.63)$ & $0.73(0.49-1.10)$ \\
\hline CVD and related risk factors & & \\
\hline Hypertension & $1.38(1.10-1.72)$ & $1.37(1.03-1.83)$ \\
\hline Stroke & $2.58(1.72-3.85)$ & $2.31(1.47-3.63)$ \\
\hline $\mathrm{CHD}$ & $0.77(0.35-1.73)$ & $0.82(0.34-1.99)$ \\
\hline Diabetes & $0.77(0.45-1.33)$ & $1.76(1.42-2.37)$ \\
\hline Family history of CVD & & \\
\hline Hypertension & $1.72(1.25-2.37)$ & $1.61(1.14-2.28)$ \\
\hline Stroke & $0.65(0.29-1.46)$ & $0.68(0.28-1.64)$ \\
\hline CHD & $0.57(0.19-1.68)$ & $0.37(0.12-1.19)$ \\
\hline Diabetes & $1.42(0.71-2.84)$ & $1.21(0.59-2.46)$ \\
\hline Lifestyle habits & & \\
\hline Cigarette smoking & $1.33(0.98-1.90)$ & $0.96(0.71-1.54)$ \\
\hline Heavy alcohol drinking & $1.32(0.99-1.77)$ & $1.56(1.00-2.17)$ \\
\hline Regular exercise & $0.83(0.57-1.21)$ & $0.73(0.49-1.08)$ \\
\hline Anxiety & $2.70(1.65-4.44)$ & $1.59(0.84-3.00)$ \\
\hline Depression & $1.72(1.30-2.26)$ & $1.59(1.04-3.00)$ \\
\hline
\end{tabular}

Abbreviation: RR, hazard ratio.

a Model 1 showed the unadjusted univariate models.

b Model 2 showed the multivariate models adjusted by age, gender and education levels. 


\section{Models, RR (95\% Cl)}

BMI (ref. 18.5-24.9)

\begin{tabular}{lll}
\hline$<18.5$ & $0.88(0.67-1.16)$ & $0.40(0.15-1.07)$ \\
\hline $25.0-29.9$ & $1.14(0.90-1.45)$ & $1.18(0.89-1.55)$ \\
\hline$\geq 30.0$ & $1.38(0.82-2.34)$ & $1.66(1.00-2.92)$ \\
\hline Net worth (RMB) (ref. $\leq 50000)$ & $1.71(1.17-2.51)$ & $1.39(0.92-2.10)$ \\
\hline$>50000$ & & \\
\hline SBP, mm Hg (ref. <140) & $1.06(0.84-1.32)$ & $1.10(0.74-1.64)$ \\
\hline 140-180 & $0.94(0.67-1.32)$ & $1.16(0.69-1.97)$ \\
\hline$>180$ & $1.17(0.91-1.50)$ & $0.83(0.61-1.14)$ \\
\hline DBP, mm Hg (ref. <90) & $1.04(0.41-2.64)$ & $0.64(0.23-1.74)$ \\
\hline $90-110$ & & \\
\hline$>110$ & $0.97(0.76-1.25)$ & $1.03(0.69-1.53)$ \\
\hline TC, mmol/L (ref. <5.7) & $1.03(0.82-1.29)$ & $0.94(0.72-1.24)$ \\
\hline$\geq 5.7$ & $0.96(0.74-1.25)$ & $0.99(0.66-1.50)$ \\
\hline TG, mmol/L (ref. <1.7) & & \\
\hline$\geq 1.7$ & & \\
\hline LDL-C, mmol/L (ref. <3.3) & & \\
\hline$\geq 3.3$ & & \\
\hline HDL-C, mmol/L (ref. $\geq 1.0)$ & & \\
\hline$<1.0$ & & \\
\hline Abbreviation: RR, hazard ratio. & & \\
\hline a Model 1 showed the unadjusted univariate models. & & \\
\hline b Model 2 showed the multivariate models adjusted by age, gender and education levels. & \\
\hline
\end{tabular}

\section{Discussion}

Among eastern Chinese population aged 55 years or more at high risk of CVD, we found high dementia prevalence, and the prevalence of dementia and $\mathrm{MCl}$ increased over the short period of 2018 to 2020 . Coupled with the fact that 
older age, low education levels, stroke, diabetes, hypertension and depression were significant risk factors, which were consistent with other studies $[18,19]$.

Compared with the 2018 cohort, the 2020 cohort had a higher prevalence of dementia and $\mathrm{MCl}$ at every age range. The age- gender adjusted prevalence of dementia was $10.15 \%$ in 2020 , which was about twice as high compared to the general population aged 65 or older in China (5.14\%), according to the national epidemiological survey [4]. It was also higher than that of the general population in Zhejiang province (4.9\%), but lower than the nursing homes (40.6\%) [15]. The age- gender adjusted prevalence of $\mathrm{MCl}$ was $25.46 \%$, which was also higher than that of the general population in Zhjiang province $[4,15]$.

To our knowledge, ours was one of very few surveys of dementia prevalence and trend in a population at high risk of CVD. The prevalence of CVD risk factors of this study population was relatively high. Hypertension was present almost half of the study population in 2018 and 2020, double of the global age standardized prevalence of hypertension [20, 21]. The mean total cholesterol (TC) of our study was $5.33 \mathrm{mmol} / \mathrm{L}$ in 2020 , which was higher than that of the general population $(4.63 \mathrm{mmol} / \mathrm{L})$. The stroke prevalence of $4.7 \%$ in 2018 and $4.0 \%$ in 2020 was higher than that of $2.8 \%$ among the general Chinese population aged 40 years or more [22]. Furthermore, the prevalence of regular exercises of $11.3 \%$ in 2018 and $13.7 \%$ in 2020 was relatively low, compared with that of $33.9 \%$ of Chinese residents [22]. The smoking rate of nearly $30 \%$ in 2020 among men in the study was high, while it was about $0.36 \%$ for women. And the high prevalence of alcohol abuse of more than half among men in 2020 was also of great concern and needed to be addressed.

Many factors had been associated with a risk for dementia. Consistent with previous investigations in China and other countries, our study confirmed that older age, lower education levels, heavy drinking were a strong risk factor for dementia in populations at high risk of CVD $[4,23,24]$. Prevalence of dementia had been found to be higher in women than men in some regions but not in all [14]. In our survey, being female was a protective factor for dementia. Obesity was associated with an increased risk of dementia, consistent with the hypothesis that obesity triggering vascular dementia decreased not only blood supply to the brain, but also increased fat cells that damaged the brain white matter leading to loss of cognitive and intellectual behaviors [25].

In addition, CVD including of diabetes, stroke and hypertension were important risk factors of dementia showed in this study. Other studies found that persons with diabetes had an increased risk for all cause dementia [14]. Meanwhile, some studies showed that stroke doubled the chances of developing dementia [26, 27]. Preventing diabetes, stroke, hypertension and reducing cardiovascular risk factors would be an effective way to reduce the dementia burden.

It should be mentioned that depression was a strong risk factor for dementia among this survey population. Evidence suggested that cerebrovascular changes might constitute a link between depression and dementia, it was not only epidemiologically but also biologically plausible that depression increased dementia risk [28]. Further research was needed to investigate whether successful prevention and antidepressive treatment of depression decreased the risk of dementia.

\section{Strengths And Weaknesses}

Some limitations needed to be mentioned in this study. The intervals between the two surveys were relatively short. Additional cohort survey data should be required in the future. Furthermore, the sample size was relatively small, a larger scale, larger sample size and longer period of study which including of more collected information are needed in the further. 
Despite these limitations, the strengths included that it was one of very few surveys about dementia prevalence and prevalence trend among a population at high risk of CVD in eastern China. And the study was a part of the PEACE Million Persons Project, which providing regional representative data at a population level in eastern China.

\section{Conclusion}

In conclusion, cognitive impairment is highly prevalent among elderly at high risk of CVD in eastern China, and the prevalence of dementia and $\mathrm{MCl}$ increases over the short period of 2018 to 2020. More population-based strategies should be focusing on modifiable risk factors of dementia, such as cardiovascular risk factors including of heavy drinking, obesity, depression and else. And longer studies enrolling larger populations are needed in the future.

\section{Abbreviations}

$A D$

Alzheimer's disease; MCl:Mild cognitive impairment; CVD:cardiovascular disease; PEACE:Patient-Centered Evaluative Assessment of Cardiac Events; NCCD:National Center for Cardiovascular Disease; MMSE:Mini-Mental State Examination; MoCA:Montreal Cognitive Assessment; HAD:Hospital Anxiety and Depression Scale; SD:standard deviations; HR:hazard ratios; AHR:adjusted hazard ratio; TC:total cholesterol.

\section{Declarations}

\section{Ethics approval and consent to participate}

The central ethics committee at the China National Center for Cardiovascular Disease (NCCD) and Zhejiang hospital approved this project. Written informed consent is obtained from all literate participants without cognitive decline on entry into the project. And for illiterate participants or ones with cognitive decline, their informed consent is obtained from their literate legally authorized representatives. Trial registration number: NCT02536456.

\section{Consent for publication}

Not applicable.

\section{Availability of data and material}

The data sets used or analyzed during the current study are available from the corresponding author on reasonable request.

\section{Competing interests}

The authors have no conflict of interest to report.

\section{Funding}

This work was funded by the National Science Foundation for Young Scientists of China (81803314), General project of Medical Science and Technology in Zhejiang province (2019KY001), General project of Medical Science and Technology in Zhejiang province (2018KY193). With these funding, we can get enough information in the data collection.

\section{Authors' contributions}


Substantial contributions to the conception or design of the work: Z P, Y J; Acquisition, analysis, or interpretation of data for the work: $Y \mathrm{~L}$;

Drafting the work for important intellectual content: HS, X X, H Y, X C, Y C.

All authors read and approved the final version of the manuscript.

\section{Acknowledgements}

I would thank for all those who working for this project.

\section{References}

1. World Health Organization. Dementia: a public health priority. 2018. http://www.who.int/mental_health/ publications/dementia_report_2018/en/.

2. Keivan Javanshiria ML, Waldo N, Friberga, et al. Atherosclerosis, Hypertension, and Diabetes in Alzheimer's Disease, Vascular Dementia, and Mixed Dementia: Prevalence and Presentation. Journal of Alzheimer's Disease. 2018;65(4):1247-58. doi:10.3233/jad-180644.

3. Brenda L, Plassman KM, Langa GG, Fisher, et al. Prevalence of Cognitive Impairment without Dementia in the United States. Ann Intern Med. 2008;18(6):427-34. 148 ).

4. Li YANG, Jing YAN, Xiaoqing JING, et al. Prevalence of dementia, cognitive status and associated risk factors among elderly of Zhejiang province, China in 2014. Age Ageing. 2016;0:1-5.

5. Gerstorf D, Hülür G, Drewelies J, et al. Secular changes in late-life cognition and well-being: towards a long bright future with a short brisk ending? Psychol Aging. 2015;30(2):301-10.

6. Wu YT, Fratiglioni L, Matthews FE, et al. Dementia in western Europe: epidemiological evidence and implications for policy making. Lancet Neurol. 2016;15(1):116-24.

7. Lewis H, Kuller DRPH, Rachel L, Caterina H, Rosano D, Edmundowicz, James T, Anne B. Subclinical Cardiovascular Disease and Death, Dementia, and Coronary Heart Disease in Patients 80p Years. Journal of the american college of cardiology. 2016;9(67):1013-22.

8. Li YANG, Jing YAN, Xiaoqing JING, et al. Screening for dementia in older adults: Comparison of Mini-Mental State Examination, Mini-Cog, clock drawing test and AD8. Plos one. 2016;11(12):e0168949.

9. Li Yang HaibinWu, Jin X, et al. Study of cardiovascular disease prediction model based on random forest in eastern China. Sci Rep. 2020;10:5245.

10. Lu J, Lu Y, Wang X, Li X, Linderman GC, Wu C. X, et al. Prevalence, awareness, treatment, and control of hypertension in China: data from 1.7 million adults in a population-based screening study (China PEACE Million Persons Project). Lancet. 2017;390:2549-58.

11. Lu J, Xuan S, Downing NS, et al. Protocol for the China PEACE (Patient-centered Evaluative Assessment of Cardiac Events) Million Persons Project pilot. BMJ Open. 2016;6:e010200.

12. Luis Ruano N, Araujo MScPhm, Branco M, Barreto R, Moreira S, et al. Prevalence and Causes of Cognitive Impairment and Dementia in a Population-Based Cohort From Northern Portugal. Am J Alzheimers Dis Other Demen. 2019;34(1):49-56.

13. Li YANG, Jing YAN, Xiaoqing JING, et al. Estimation of diagnostic performance of dementia screening tests: MiniMental State Examination, Mini-Cog, Clock Drawing test and Ascertain Dementia 8 questionnaire. AGING \& MENTAL HEALTH, 2018, 22, 8,942-946. 
14. Dominguez J, M. Fe de Guzman. Macario Reandelar Jr, Thien Kieu Thi Phung. Prevalence of Dementia and Associated Risk Factors: A Population-Based Study in the Philippines. Journal of Alzheimer's Disease. 2018; 63: 1065-1073.

15. Li YANG, Xiaoqing JING, Jing YAN, Jin Yu, Xu S, Xu Y, Liu C, Yu W, Zheng P. Comparison of prevalence and associated risk factors of cognitive function status among elderly between nursing homes and common communities of China: A STROBE-Compliant Observational Study. Medicine. 2019;11.

16. Chinese Dementia and cognitive Impairment Diagnosis and treatment guidelines collaboration group. Professional Committee of Cognitive Impairment diseases, Neurologist Branch, Chinese Medical Doctor Association. Chinese Guidelines for the Diagnosis and Treatment of Dementia and Cognitive Disorders in 2018. Natl Med J China. 2018;98(15):1125-9.

17. Jianping Jiaa F, Wang C, Wei AZ, Jia X, Li F, et al. The prevalence of dementia in urban and rural areas of China. Alzheimer's Dementia. 2018;10:1-9.

18. Gershwin Davis N, Baboolal AM, Rae, Robert Stewart. Dementia prevalence in a population at high vascular risk: the Trinidad national survey of ageing and cognition. BMJ Open. 2018;8:e018288.

19. Katon W, Pedersen HS, Ribe AR, Fenger-Grøn M, Davydow D, et al. Effect of Depression and Diabetes Mellitus on the Risk for Dementia A National Population-Based Cohort Study. JAMA Psychiatry. Published online April 15, 2015. doi:10.1001/jamapsychiatry. 2015.0082.

20. Dominguez J, M. Fe de Guzman, Reandelar M Jr, et al. Prevalence of Dementia and Associated Risk Factors: A Population-Based Study in the Philippines. Journal of Alzheimer's Disease. 2018;63:1065-1073. doi:10.3233/JAD-180095.

21. NCD Risk Factor Collaboration (NCD-RisC). Worldwide trends in blood pressure from 1975 to 2015: A pooled analysis of 1479 population-based measurement studies with 19 million participants. Lancet. 2016;389:37-55.

22. Chinese Cardiovascular health and Disease Report Writing Group. Summary of China's Cardiovascular Health and Disease Report 2019. Chinese Circulation Journal. 2020;35(9):833-54.

23. Horst Bickel I, Hendlmeier JB, Heßler. Magdalena Nora Junge, Sarah Leonhardt-Achilles, Joshua Weber, Martina Schäufele. The Prevalence of Dementia and Cognitive Impairment in Hospitals. Dtsch Arztebl Int. 2018;115:73340.

24. Kalaria RN, Maestre GE, Arizaga R, Friedland RP, Galasko D, Hall K, et al. Alzheimer's disease and vascular dementia in developing countries: prevalence, management, and risk factors. Lancet Neurol. 2008;7:812-26.

25. Ibrar Anjum MF, Wajid A, et al. Does Obesity Increase the Risk of Dementia: A Literature Review. Cureus. 2018;10(5):e2660. DOI 10.7759/cureus.2660.

26. Vladimir Hachinski K, Einhäupl D, Ganten S, Alladi C, Brayne, Blossom CM, Stephan, et al. Preventing dementia by preventing stroke: The Berlin Manifesto. Alzheimers Dement. 2019;15(7):961-84.

27. Kuzma E, Lourida I, Moore SF, Levine DA, Ukoumunne OC, Llewellyn DJ. Stroke and dementia risk: A systematic and meta-analysis. Alzheimers Dement. 2018;14:1416-28.

28. Isabelle Bos, Stephanie JB, Vos SE, Schindler J, Hassenstab C, Xiong E, Grant, et al. Vascular risk factors are associated with longitudinal changes in cerebrospinal fluid tau markers and cognition in preclinical Alzheimer disease. Alzheimers Dement. 2019;15(9):1149-59. 